\title{
Gilles Bancarel, Raynal ou le devoir de vérité
}

\section{Olga Penke}

\section{OpenEdition}

\section{Journals}

\section{Édition électronique}

URL : http://journals.openedition.org/studifrancesi/30337

DOI : 10.4000/studifrancesi.30337

ISSN : 2427-5856

\section{Éditeur}

Rosenberg \& Sellier

\section{Édition imprimée}

Date de publication : 1 avril 2006

Pagination : 161

ISSN : 0039-2944

\section{Référence électronique}

Olga Penke, «Gilles Bancarel, Raynal ou le devoir de vérité », Studi Francesi [En ligne], 148 (XLX | I) | 2006, mis en ligne le 30 novembre 2015, consulté le 22 avril 2021. URL : http://journals.openedition.org/ studifrancesi/30337 ; DOI : https://doi.org/10.4000/studifrancesi.30337

\section{Ce document a été généré automatiquement le 22 avril 2021.}

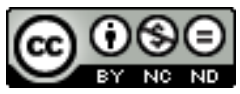

Studi Francesi è distribuita con Licenza Creative Commons Attribuzione - Non commerciale - Non opere derivate 4.0 Internazionale. 


\title{
Gilles Bancarel, Raynal ou le devoir de vérité
}

\author{
Olga Penke
}

\section{RÉFÉRENCE}

GILLES BANCAREL, Raynal ou le devoir de vérité, Honoré Champion, Paris, 2004 («Les dix-

huitièmes siècles») pp. 652.

1 Cette biographie de Guillaume-Thomas Raynal retrace le récit de l'existence de l'homme, de l'historien et du philosophe, son environnement social et culturel ainsi que la genèse et la destinée de l'Histoire des deux Indes, œuvre collective à laquelle Raynal voue la moitié de sa vie. Le livre se place dans le prolongement des recherches sur Raynal, commencées dans les années vingt du vingtième siècle et approfondies grâce aux colloques internationaux organisés au cours des vingt dernières années du siècle passé.

2 L'auteur s'appuie sur des études antérieures qu'il complète considérablement suivant quatre axes principaux. La famille et les relations personnelles, liées aux milieux de la noblesse provinciale et du négoce international, déterminent les origines sociales et culturelles de Raynal ( $\mathrm{I}^{\mathrm{e}}$ partie "Aux origines d'une vocation»). Fondamentalement intéressé par l'histoire et la diplomatie, ses premiers écrits reflètent déjà ses goûts politiques et militaires. Ses activités académiques multiples, amplement présentées, démontrent les mêmes centres d'intérêt et témoignent en même temps de sa volonté de participer au mouvement scientifique et littéraire européen de l'époque. L'intérêt historique et académique est complété par ses préoccupations de réaliser une histoire des idées protestantes et du sort des réfugiés dispersés dans le monde (II ${ }^{\mathrm{e}}$ partie «La maîtrise de l'écriture»). Ses affinités avec la Suisse, l'Europe des Lumières et l'Amérique influent sur ses différentes activités et déterminent également le jugement équivoque qui caractérise son accueil contemporain (III ${ }^{\mathrm{e}}$ partie «La littérature comme instrument»). Son exil à l'étranger, son retour non-officiel et la cassation du décret de 
prise de corps par l'Assemblée Nationale en 1790, tout comme ses prises de position publiques et politiques jouent un rôle incontestable dans ses relations humaines et la reconnaissance composite de son œuvre (IVe partie «Le choc de la réalité»).

3 Le livre publie une multitude de documents sur la vie et le succès de l'œuvre de l'abbé Raynal: lettres, extraits de revues et de mémoires de l'époque, textes mal connus, oubliés, souvent inédits. L'«Annexe» du livre ajoute des documents particulièrement précieux (parmi lesquels la célèbre Adresse à l'Assemblée Nationale (1791), un tableau récapitulatif des prix qu'il a fondés et une iconographie très riche) qui permettent de mieux comprendre le contexte culturel de l'œuvre. L'auteur de cette vaste biographie désigne aussi les tâches blanches des recherches actuelles, renvoyant aux insuffisances documentaires. 